\title{
Risk of the loess pseudo-karst development during construction and its link with natural and technogenic processes
}

\author{
Andrey Lavrusevich ${ }^{1, *}$ \\ ${ }^{1}$ Moscow State University of Civil Engineering, Yaroslavskoye Shosse, 26, 129337, Moscow, Russia
}

\begin{abstract}
Crowning the tops of geological cuts and occupying considerable territories in favorable physiographic conditions, loess rocks are the very basis, which have been actively used by human society since ancient times. For example, the Loess plateau in China is the place of origin of the Chinese civilization. The loess pseudo-karst began to develop actively in loess massifs because of development of a technogenesis and active construction of civil, industrial and hydraulic engineering constructions, water supply on earlier not-developed territories for agricultural development. This dangerous geological phenomenon leads to the destruction of structures, initiates development of landslides, collapses, mud streams, ravines and as the result, quite often forms pseudo-karstic bad land. Cases, when the increase in danger of a loess pseudo-karst at high degree of vulnerability of structures, resulted both in economic and social risk are known. Knowledge of principles of danger assessment of the loess pseudo-karst development during construction and maintenance of structures of different purposes as well as the developments which have not been involved in economic activity earlier will allow minimizing economic and social damages.
\end{abstract}

\section{Introduction}

Loess rock formations is the unique natural phenomenon. They possess some special properties, including ephemeral properties, which distinguish them from all the variety of formations of the Quaternary Period [1]. Such properties as high porosity (up to 57\%), low humidity, existence of carbonates, unstable structural communications, ability to subsidence and ability to a pseudo-kart formation, small number of readily soluble connections, ability to form and hold long periods vertical slopes, etc. are characteristic only of loess rocks [2].

For example, cases of vertical boards of technogenic ravines up to 70 high and even 90 $\mathrm{m}$, formed because of uncivilized dumping of irrigation waters from cotton plantations are noticed in the mountain camp Tajikistan. In Xinjiang (the largest territorial administrative unit on the area in the northwest of China) height of such breaks reaches $80-100$ meters [3]. The high fertility of soils of the crops allowing to receive rich harvests (millet, gaolyan, wheat, fruit and berry) is connected with the loess, and in case of irrigation there are rich

\footnotetext{
${ }^{*}$ Corresponding author: lavrusevich@yandex.ru
} 
harvests of cotton and even the most valuable fine-fibered cotton culture. The loess covers more than 13 million sq.km or about $10 \%$ of the surface of more ancient rocks of the mainland of the planet. Loess rocks were and remain the unique construction material, they can be considered as the most valuable mineral and raw resource, prepared by the Nature on the surface of continents of the Earth [4].

Only Antarctica is free from the loess "blanket". The classical place of distribution of loess rocks are certainly China and Central Asia. In China the loess deposits reach $500 \mathrm{~m} \mathrm{[5],}$ and the Loess plateau, according to archeological finds, is the place of origin of the Chinese civilization. Loess rocks usually lie in the form of an integumentary cover on the terrace surfaces and foothill plains and in the places of transition from the leveled surfaces to mountains as well. This step of transition from the plain to mountains is widespread in Asia quite widely and it carries the name of adyr.

The most interesting bedding of the loess with its distribution is at the tops of the isolated watersheds. Such phenomena described by F. Rikhtgofen, V.A. Obruchev [6, 7], etc. Usually upper bound of distribution of loess rocks lies within 2000-2500 $\mathrm{m}$ above the sea level. V.T. Trofimov mentions finding of loess rocks in the form of small separate sites at the heights up to $3000-4500 \mathrm{~m}[8]$.

\section{Materials and Methods}

In case of the change of moisture conditions as the result of violation of integrity of the loess massif or in case of change of its natural state (deforestation, violation of the cespitose cover, irrigation and uncivilized dumping of water surplus) active erosive processes, within which loess formations lose the unique properties begin and turn into loess-like loams. This degradation of the loess is irreversible [8].

Degradation of loess massifs is shown in the form of the whole series of the difficult physical and chemical processes, which sometimes pass very promptly and have serious consequences for the environment and structures, built by the human.

Besides the ability to subsidence, such prompt and rapid process as loess pseudo-karst is taking place due to the active technogenic load of loess massifs from the second half of the 20th century. Technogenez is the main reason for the development of the loess pseudo-karst. Technogenez is considered as the process of change of natural complexes and biogeocenoses because of production economic activity of the human [9]. Loess pseudo-karst is the process of the hydrodynamic, gravitational, physical and chemical and biological zone processes proceeding in the undercompacted loess rocks in case of their superfluous, incidental (usually technogenic) moistening of the forms of the relief leading to education reminding typical karstic (holes, funnels, caves, wells, ravines, circuses, etc.) [10].

The main feature of the loess pseudo-karst is the high speed of its formation, especially in case of technogenic loading.

The mechanical suffusion as the result of turbulent, usually vertical movement of water is dominating, there is a free separation of dusty particles of the loess as the content of watersoluble connections is from 1 to $1.5 \%$ of the weight of rock [11].

Therefore in case of receipt of the great amount of water, the process develops very promptly (in Tajikistan the case, because of the water leak from concrete water trays, the pseudo-karst appeared in 1 day and a half, (its visible depth was $5 \mathrm{~m}$ width was $8 \mathrm{~m}$ and the length was more than 30 meters) [12]. In the Western branch of the Nadterechny channel (East Ciscaucasia) the holes forms in the form of funnels and holes with the diameter up to $1.5 \mathrm{~m}$ have left on the normal to an axis of the channel on 900 meters from its edge $[13,14]$.

Misunderstanding of this process has led to some wrong decisions on preparation of the bases for explosive objects, treatment objects and housing for the world's largest Prikumsky plant of plastic in Budyonnovsk. During preconstruction soaking of ditches with drainage 
wells, holes and funnels in collapsible soil with power up to $50 \mathrm{~m}$ were formed there. It has led to big (by 3-4 times) to the excessive consumption of water, scarce in steppe areas, and a delay of construction of the state objects.

The loess pseudo-karst has led to the emergencies during maintenance of the objects of the Great Stavropol Canal (GSC), which is the largest in Russia, it has gained its development on the steep coast of the Terek River in the territory of Chechen-Ingushetia. This hidden process is especially dangerous during elimination of the ability to subsidence of powerful loess thicknesses by preliminary soaking of ditches. Therefore, engineers often refuse the "standard" methods of elimination of the subsidence soaking of loess soil [11].

That is a paradox, but the development of the loess pseudo-karst has some positive moments. However, at once we will make a reservation that it can occur only in case of its natural origin, when the loess pseudo-karst slowly develops in the low-developed and vacant territories. In this case, it is possible to remember the caves of pseudo-karst origin having esthetical, scientific, informative, and recreational value. It is enough to give the example of a pseudo-karst cave in the loess near the settlement of Surduk on the bank of Danube in Serbia, where the famous film director Emir Kusturica made several plots for the well-known movies [15].

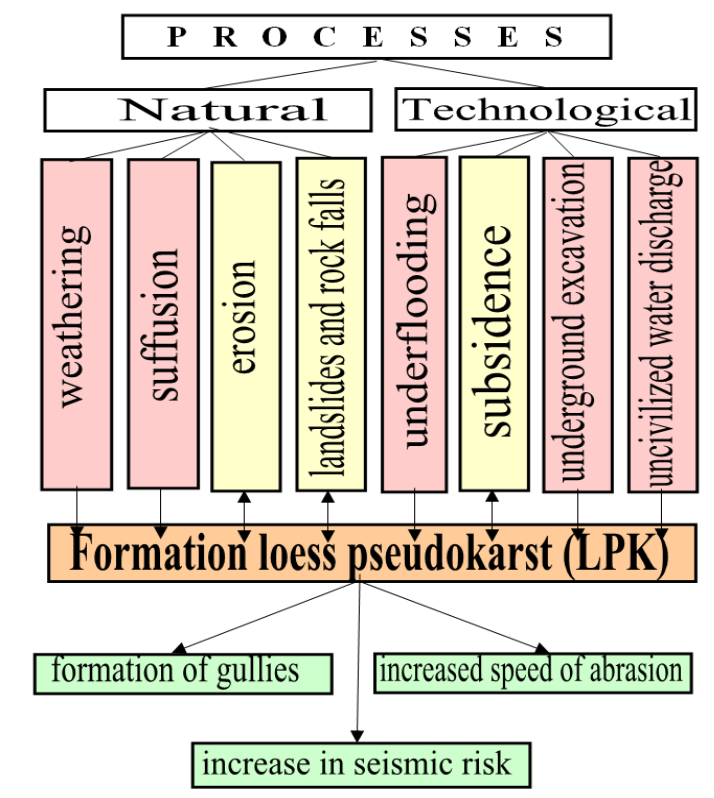

Fig. 1. The nature of interaction of some natural and technogenic processes with the loess pseudokarst.

The factors promoting formation of the pseudo-karst are divided into natural and technogenic. The nature of interaction of some natural and technogenic processes with the loess pseudo-karst is briefly described in figure 1 and table 1.

The most intensive development of the loess pseudo-karst happens in case of technogenic load of loess massifs. In natural conditions, the loess pseudo-karst develops slowly and does not strike great areas. 
Table 1. Some processes and nature of their interrelation with the loess pseudo-karst.

\begin{tabular}{|c|c|c|c|}
\hline & $\begin{array}{l}\text { The nature of the interaction of } \\
\text { some natural and technogenic } \\
\text { processes of loess pseudo karst }\end{array}$ & 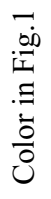 & Description of processes \\
\hline 1 & $\begin{array}{l}\text { Processes that play exclusively } \\
\text { catalytic role in the formation of } \\
\text { loess pseudo karst (LPK) }\end{array}$ & & $\begin{array}{l}\text { Factors weathered loess arrays. In particular, } \\
\text { biological destruction, contributing to the formation } \\
\text { of underground tunnels which begins penetration of } \\
\text { water in loess and the beginning of an array of } \\
\text { suffusion, as the process of forming the initial pseudo } \\
\text { karst forms in destruction of loess array. Education } \\
\text { the pseudo karst failures of resulting underflooding. } \\
\text { Pseudo karst development in places where } \\
\text { underground excavation of loess. The pseudo karst } \\
\text { badlands formation in areas uncivilized water } \\
\text { discharge. }\end{array}$ \\
\hline 2 & $\begin{array}{l}\text { Processes play a catalytic role } \\
\text { in the formation of loess pseudo } \\
\text { karst (LPK) and the induced its } \\
\text { formation. }\end{array}$ & & $\begin{array}{l}\text { Primary education of pseudo karst underground } \\
\text { tunnels enhances erosion (increase capacity moves). } \\
\text { The process is multiplicative. Landslides and rock } \\
\text { falls in loess promotes formation of deep cracks in the } \\
\text { upper part of the slope. As a result of uneven } \\
\text { subsidence while soaking formed deep cracks forming } \\
\text { of pseudo karst landforms. }\end{array}$ \\
\hline 3 & $\begin{array}{l}\text { Processes induced by the } \\
\text { formation of loess pseudo karst } \\
\text { (LPK) and exacerbated by its } \\
\text { development. }\end{array}$ & & $\begin{array}{l}\text { Development of pseudo karst gullies, formation, } \\
\text { which occurs from the top down to the base level. } \\
\text { Increased several times abrasion loess shores of } \\
\text { reservoirs affected pseudo karst. By breakage array } \\
\text { pseudo karst increases seismicity loess area, which } \\
\text { may result in the display of the earthquake subsidence, } \\
\text { landslides and avalanches. }\end{array}$ \\
\hline
\end{tabular}

\section{Results}

During development of the loess territory it is necessary to show the level of danger of the loess pseudo-karst which depends both on the level of danger of the most pseudo-karst process, and on the degree of vulnerability of the loess territory [16].

The geological danger of the loess pseudo-karst is the threat of formation of new or activation of the existing underground and superficial pseudo-karst forms of the relief with certain parameters in the loess territory (the loess massif) for the set period, which pose a threat for life or welfare of people, objects of the economy or the environment [17].

Justification of level of danger of the loess pseudo-karst is made based on these engineering-and-geological as well as engineering-and-ecological researches. Assessment of danger of the loess pseudo-karst is the main objective of the forecast of the development of the pseudo-karst in this territory, which consists of the loess rocks.

In case defeat of the loess rock massif by the pseudo-karst, it stops being a rather reliable basis for any structure, or loses the function of reproduction of agricultural products, owing 
to the violation of integrity of the massif and also can represent some level of danger if the extent of the pseudo-karst development exceeds some critical frame. It results in the need to characterize the arising danger (qualitative and quantitative as well).

The methodology, based on the principle of introduction of integrated quantitative "criterion of proximity to an ideal point" is used for this purpose. The principle of an ideal point is one of heuristic approaches, which brings the problems of multicriteria optimization to the problem of one-dimensional optimization. The problem of multicriteria optimization is rather difficult field of mathematics, which is studied a little, therefore theoretical justification of the creation of tables of ordering of codes of danger and vulnerability is rather difficult. Nevertheless, "the criterion of proximity to an ideal point", has proved to be reliable for the solution of such tasks [18].

The analysis of the research results for the factors of the defeat of the territory the loess pseudo-karst allows to recommend the following key indicators of danger ranged according to the importance (from 0.1 to 0.9 ): 1 ) prevalence of the territory loess pseudo-karst; 2) speed of development of the loess pseudo-karst; 3 ) change of properties of the loess, composing the massif as the result of development of the loess pseudo-karst; 4) change of hypsometric marks of the surface of the loess massif; 5) the induced dangerous geological processes [1,2]. Each of the indicators is estimated on the following serial scale: 0 - safe state; 1 - low level of danger; 2 - medium level of danger; 3 - great level of danger.

The presented order of introduction of numbers and codes allows to give the characteristic of process of defeat of the territory by the loess pseudo-karst. If it is written down numerically (for example, the code of 5 symbols - 12003 - means, that the first indicator of danger (the first figure, i.e. the first number) represents low danger of defeat of the territory, the second indicator of danger (the second figure) is pointed to the medium level of danger of flooding, and the third and fourth indicators of danger do not cause any danger from the point of view of defeat of the territory by the loess pseudo-karst. Great level of danger of defeat of the territory by the loess pseudo-karst is characteristic of the last indicator of danger (the last figure 3).

Thus, it is necessary to have a ratio among the indicators of process of defeat and codes of danger based on which the danger coefficient, i.e. the quantity which can be counted and used for justification of the need of protective measures can be calculated.

The concept "vulnerability" needs to be entered and investigated during the assessment of risk of defeat by the loess pseudo-karst first of all because it (this concept) allows to separate the danger of defeat the from risk of defeat, which are obviously or implicitly often identified in literature. It quite often takes place, when any quality standard of the negative processes, connected with defeat by the pseudo-karst, is given.

The matter is that the same assessment of danger of defeat by the pseudo-karst of different territories can lead to such negative consequences, which on the scales can be incommensurable. It is connected with features of the territory, its functional purpose, existence of any communications and objects in this territory, ability of these objects to react to negative development of processes of defeat by the loess pseudo-karst, susceptibility to the dangerous impact of the defeat by the loess pseudo-karst.

\section{Discussion}

Thus, 5-measured vector of rankings, characterizing the level of danger of the loess pseudokarst are delivered to each concrete engineering-and-geological object (territory) in compliance. It is known that the vector in dimension spaces more than 1 cannot be ordered naturally, therefore, for the possibility of ordering of engineering-and-geological objects according to the danger level, it is necessary to use one of artificial methods of their ordering. 
It is offered to use the method of an ideal point of Verzhbitsky, which main idea consists in introduction of one or several ideal points in multidimensional space and in ordering of the vectors, characterizing the danger level on specially entered function of the distance from a concrete point in multidimensional space to the ideal point, priori set. It should be noted, that this approach has proved to be good for the solution of the tasks of assessment of geological risk in Moscow [4].

We enter the dimensionless coefficient of danger $\lambda_{0}$, which has to reflect that place of the considered process in this territory, which it takes between "ideal" option $\left(\lambda^{\mathrm{id}}{ }_{0}=0\right)$ and the negative "ideal" option $\left(\lambda^{\text {nd }}=1\right)$.

Then the function of distance (integrated criterion of level of danger) can be calculated as

$$
\lambda_{0}=k_{\text {norm }} \sum_{i=1}^{N} \delta_{i} a_{i}
$$

where $\delta_{i}$ - coefficient of the importance of the $\mathrm{i}_{\text {th }}$ indicator of danger (the value, established by the expert-analyst from 0.1 to 0.9 ); $a_{i}$ - value of the $i_{\text {th }}$ indicator of danger point; $\mathrm{k}_{\text {norm }}$ - the normalizing multiplier, bringing to $0 \leq \lambda_{0} \leq 1$.

The final result of this technique are presented in table 2 .

Table 2. Assessment of coefficient of danger of defeat of the territory by the loess pseudo-karst $(=0.0980)$ (fragment).

\begin{tabular}{|l|l|l|l|l|l|l|l|}
\hline $\begin{array}{l}\text { Code of } \\
\text { danger }\end{array}$ & $\lambda_{0}$ & $\begin{array}{l}\text { Code of } \\
\text { danger }\end{array}$ & $\lambda_{0}$ & $\begin{array}{l}\text { Code of } \\
\text { danger }\end{array}$ & $\lambda_{0}$ & $\begin{array}{l}\text { Code of } \\
\text { danger }\end{array}$ & $\lambda_{0}$ \\
\hline 00000 & 0,0000 & 03221 & 0.4902 & 13333 & 0.8431 & 23333 & 0.9216 \\
\hline 00002 & 0.1765 & 03310 & 0.4216 & 20002 & 0.3333 & 30002 & 0.4118 \\
\hline 00131 & 0.2647 & 03332 & 0.6765 & 20131 & 0.4216 & 30131 & 0.5000 \\
\hline 00023 & 0.3431 & 03333 & 0.7647 & 20023 & 0.5000 & 30023 & 0.5784 \\
\hline
\end{tabular}

The use of the Verzhbitsky method of an ideal point is similar; ordering of engineeringand-geological objects on vulnerability degree by the loess pseudo-karst can be carried out

Table 3. Assessment of coefficient of vulnerability of the territory ( $=0.0758$ ) (fragment).

\begin{tabular}{|l|l|l|l|l|l|l|l|}
\hline $\begin{array}{l}\text { Vulnerabilit } \\
\text { y code }\end{array}$ & $v_{y}$ & $\begin{array}{l}\text { Vulnerability } \\
\text { code }\end{array}$ & $v_{y}$ & $\begin{array}{l}\text { Vulnerability } \\
\text { code }\end{array}$ & $v_{y}$ & $\begin{array}{l}\text { Vulnerability } \\
\text { code }\end{array}$ & $v_{y}$ \\
\hline 00000000 & 0,0000 & 00020101 & 0,1515 & 00220101 & 0,2273 & 10220101 & 0,2955 \\
\hline 00000002 & 0.0455 & 00020120 & 0,1894 & 00220120 & 0,2652 & 10220120 & 0,3373 \\
\hline 00000013 & 0,0985 & 00020133 & 0,2879 & 00220133 & 0,3636 & 10220133 & 0,4318 \\
\hline 00000021 & 0,0833 & 00020202 & 0,2121 & 00220202 & 0,2879 & 10220202 & 0,3561 \\
\hline
\end{tabular}

The coefficient of risk of defeat of the territory by the loess pseudo-karst is estimated as follows: $R_{n}=\lambda_{0} \cdot v_{y}$

For the territory across which the division into districts according to the level of danger and vulnerability, the coefficient of risk of defeat by the loess pseudo-karst of the territory $R_{n}$ is estimated as follows:

$$
R_{n}=\frac{\sum_{i=1}^{k} v_{y i} \cdot \lambda_{0 i} \cdot S_{i}}{S_{0}}
$$


where $S_{0}$ - the area of the territory for which the coefficient of risk of defeat by the loess pseudo-karst is estimated $R_{n}$;

$$
S_{0}=\sum_{i=0}^{k} S_{i}
$$

where $k$ - number of the broken sections of the area $S_{0}$ on the areas, which are not crossed among themselves $S_{i}$, for which coefficients of danger of defeat by the loess pseudo-karst are estimated and known $\lambda_{0 i}$ and vulnerabilities of defeat by the loess pseudo-karst $v_{y i}$.

\section{Conclusion}

The presented order of introduction of numbers and codes of indicators of danger and vulnerability allows to characterize the territory from the point of view of the assessment of its susceptibility to the danger of defeat by the loess pseudo-karst. Thus, the procedure of calculation of coefficient of vulnerability of the territory comes down to the assignment of a code of this territory and establishment of communication between this code and coefficient of vulnerability.

The coefficient, which is called the coefficient of risk of defeat of the territory by the loess pseudo-karst, is entered.

This coefficient does not establish the damage in itself from the defeat by the loess pseudo-karst, and only characterizes it, i.e. the higher it is, the damage is more possible and vice versa - the smaller coefficient of risk indicates means the smaller level of damage. From (3) follows, that even for great coefficient of danger of defeat of the territory by the loess pseudo-karst the risk of defeat of the territory by the loess pseudo-karst can be small, if the coefficient of vulnerability of the territory is small. On the contrary, if the vulnerability of the territory is great, and the danger of defeat of the territory by the loess pseudo-karst is small, then the risk can be small.

\section{References}

1. N.I. Krieger, Loess, formation of collapsible properties (Science, Moscow, 1986)

2. M.P. Lysenko, Structure and physicomechanical properties of soil (Subsoil, Moscow, 1972)

3. F.A. Rakhmatullin, News of the Kyrgyz branch Academy of Sciences of the USSR IIXII, 41-46 (1954)

4. A.A. Lavrusevich, Investigation and protection of subsoil 7, 44-47 (2012)

5. Li Si-guan, Geology of China (Foreign literature, Moscow, 1952)

6. F. Richthofen, China (Bd., Berlin, 1877)

7. V.A. Obruchev, From Kyakhta to Kuldzhi. Travel to Central Asia and China (Academy of Sciences, Moscow, 1940)

8. V.T. Trofimov, Engineering geology of massifs of loess rocks (Moscow publishing house, Moscow, 2008) 
9. N.F. Reymers, Environmental management. Dictionary reference (Thought, Moscow, 1993)

10. A.A. Lavrusevich, V.S. Krasheninnikov, I.A. Lavrusevich, Engineering geology 1, 4858 (2012)

11. N.I. Krieger, V.I. Botnikov 3, 48-51 (1983)

12. A.A. Lavrusevich, V.P. Homenko, MGSU Bulletin 10, 213-221 (2012)

13. I.G. Glukhov, Hydraulic engineering and melioration 10, 9-18 (1956)

14. E.V. Zaporozhchenko, Questions of construction of hydraulic engineering constructions on collapsible soil, 108-115 (1969)

15. T. Lukić, S. Marković, Acta Carsologica 38/2-3, 227-235 (2009)

16. A.A. Lavrusevich, International conference. Engeopro, 215-218 (2011)

17. A.L. Ragozin, Natural dangers of Russia. Volume 6. Assessment and management of natural risks (Moscow, 2003)

18. Recommendations on the assessment of geological risk in the territory of Moscow (GUP "NIATs", Moscow, 2002) 